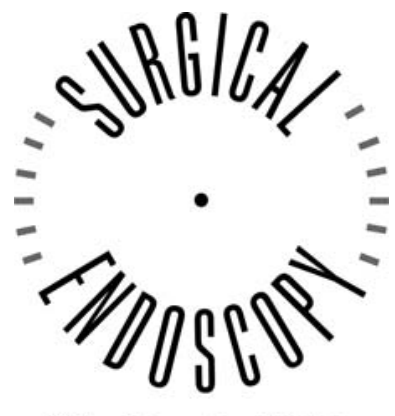

and Other Interventional Techniques

\title{
Minimally invasive pediatric surgery: Increasing implementation in daily practice and resident's training
}

\author{
E. A. te Velde, ${ }^{1}$ N. M. A. Bax,${ }^{2}$ S. H. A. J. Tytgat, ${ }^{1}$ J. R. de Jong, ${ }^{1}$ D. Vieira Travassos, ${ }^{1}$ W. L. M. Kramer, ${ }^{1}$ \\ D. C. van der Zee ${ }^{1}$ \\ ${ }^{1}$ Department of Pediatric Surgery, Wilhelmina Children's Hospital, University Medical Center, Utrecht, The Netherlands \\ ${ }^{2}$ Department of Pediatric Surgery, Sophia Children's Hospital, University Medical Center, Rotterdam, The Netherlands
}

Received: 21 January 2007/Accepted: 11 February 2007/Online publication: 5 May 2007

\begin{abstract}
Background: In 1998, the one-year experience in minimally invasive abdominal surgery in children at a pediatric training center was assessed. Seven years later, we determined the current status of pediatric minimally invasive surgery in daily practice and surgical training. Methods: A retrospective review was undertaken of all children with intra-abdominal operations performed between 1 January 2005 and 31 December 2005.

Results: The type of operations performed ranged from common interventions to demanding laparoscopic procedures. $81 \%$ of all abdominal procedures were performed laparoscopically, with a complication rate stable at $6.9 \%$, and conversion rate decreasing from $10 \%$ to $7.4 \%$, compared to 1998 . There were six new advanced laparoscopic procedures performed in 2005 as compared to 1998 . The children in the open operated group were significantly smaller and younger than in the laparoscopic group ( $p<0.001$ and $p=0.001$, respectively). The majority $(64.2 \%)$ of the laparoscopic procedures were performed by a trainee. There was no difference in the operating times of open versus laparoscopic surgery, or of procedures performed by trainees versus staff surgeons. Laparoscopy by trainees did not have a negative impact on complication or conversion rates.

Conclusions: Laparoscopy is an established approach in abdominal procedures in children, and does not hamper surgical training.
\end{abstract}

Key words: Pediatric surgery - Minimally invasive surgery - Training

Correspondence to: E. A. te Velde

\section{Background}

In adults, the known advantages of minimally invasive surgery are improved cosmesis due to smaller incisions, and fewer postoperative ileus and pain, which results in less analgesic use, less respiratory morbidity, shorter hospital stays, and a swift return to preoperative activities [1]. In pediatric surgery, minimally invasive surgery has been introduced at a slower pace, in part because the patients are smaller, the operations are often already performed through small incisions, and many of the conditions that require surgery are rare, and therefore require a longer training period [2]. Davenport stated in 2003 that the majority of procedures in children were still conventional rather than laparoscopic [3]. In addition, in the early 1990s, prudence was widely advocated $[4,5]$ and it is well known that a surgeon's experience and learning curve are very important predictors of outcome.

On the other hand, in 1998 we found that of all abdominal surgery performed in our hospital, already as much as $60 \%$ had been performed by minimally invasive techniques as opposed to laparotomy, with a conversion rate of $10.1 \%$ (mainly appendicitis) and a complication rate of $6.8 \%$ [6]. Moreover, as we described earlier, trainees easily learned the laparoscopic pyloromyotomy procedure without any increase in the complication rate [7]. However, it could be speculated that with an increase in laparoscopic procedures, the surgical training of a trainee might be compromised since the procedures are more strenuous than in open surgery and therefore require intensive training.

In this study we retrospectively assessed all consecutive abdominal surgical procedures in 2005. We evaluated the current use of minimally invasive surgery and open surgery in pediatric patients, in order to determine its role in the training of surgical trainees. 
Table 1. Patient characteristics

\begin{tabular}{llcl}
\hline & Open & Laparosopy & \\
\hline Median age (range) & $15(0-25$ weeks $)$ & 76 weeks $(0$ days-17 years $)$ & $p=0.001$ \\
Under one year of age & $30(68.1 \%)$ & $89(48.7 \%)$ & $25(14.4 \%)$ \\
Under four weeks of age & $20(45.5 \%)$ & $8.2(0.76-90)$ & $p<0.001$ \\
Mean weight, in kg (range) & $3.6(0.76-61)$ & 0 \\
\hline
\end{tabular}

\section{Patients and methods}

All consecutive children undergoing an abdominal surgical procedure in the Department of Pediatric Surgery of the University Medical Center Utrecht during a period of one year (1 January 2005 to 31 December 2005) were included. All medical data was retrieved from the patients' files, including gender, age, weight, procedure, emergency or planned, operating surgeon (one surgical resident, two fellows and four staff surgeons), duration of operation, intraoperative surgical and technical problems, conversions, and complications. Well-supervised surgical residents and fellows in pediatric surgery - henceforth referred to as trainees, unless stated otherwise - were distinguished from staff surgeons, and it was noted by whom a procedure was performed. A procedure was defined as an emergency procedure when it was performed within 12 hours after diagnosis. The pyloromyotomies were considered a planned procedure. The postoperative course was reviewed, and complications, reinterventions and time to follow-up were assessed. The type of operation was graded according to its complexity as easy, difficult, or demanding using the grading of Costi et al. for laparoscopic procedures in adults [8], modified for pediatric laparoscopies by Metzelder et al. [9].

For the record, it should be noted that in our department no resections of solid tumors or urologic procedures are performed.

For laparoscopic procedures, a standard open introduction technique of the first port through the inferior umbilical fold was used. Laparoscopy was performed routinely with reusable instruments and devices, mostly 3-5 mm ports (Storz ${ }^{\circledR}$ Tutlingen, Germany). The maximum intra-abdominal pressure was kept at $8 \mathrm{mmHg}$ and the maximum flow at $5 \mathrm{~L} / \mathrm{min}$ in older children, and at $5 \mathrm{mmHg}$ and $2 \mathrm{~L} /$ min in infants. Monopolar electrocautery devices were used. At the end of the operation all port sites were closed by use of a resorbable suture. In laparoscopic-assisted surgery, dissection was performed laparoscopically followed by a small local incision to perform an anastomosis outside of the abdominal cavity.

Statistical analysis was performed using independent sample Mann-Whitney $t$-test.

Significance was determined by a $p$ value less than 0.05 . SPSS (Inc Chicago, Illinois) software package for Windows was used. Results are presented as mean \pm standard deviation, or median (range).

\section{Results}

In total, 231 patients underwent abdominal surgery in 2005 , of which $44(18.9 \%)$ were performed via laparotomy and 187 (81\%) were performed laparoscopically. Patient characteristics are summarized in Table 1.

As compared to 1998, six new procedures were performed in a minimally invasive fashion in 2005 $(n=14)$, of which all but one were classified as demanding procedures, and are indicated by an asterisk in Table 3. A trainee was the operating surgeon in $72.7 \%$ of the open procedures (Table 2) versus $64.2 \%$ in the laparoscopic group (Table 3). The percentage of the laparoscopic procedures classified as difficult and performed by a trainee was $48 \%$.

Of the open procedures, $40.9 \%$ were planned compared to $74.8 \%$ of the laparoscopic procedures. Of the minimally invasive procedures, the trainees performed
Table 2. Indications for laparotomy

\begin{tabular}{llll}
\hline & Total & $\begin{array}{l}\text { Number } \\
\text { performed } \\
\text { number trainees }\end{array}$ & $\begin{array}{l}\text { Number } \\
\text { performed } \\
\text { by staff } \\
\text { surgeons }\end{array}$ \\
Laparotomy & & & \\
\hline Easy & 3 & 2 & 1 \\
Appendectomy & 3 & 3 & \\
CAPD* & & & \\
Difficult & 10 & 7 & 3 \\
Entero-enterostomy/adhesiolysis & 8 & 5 & 3 \\
Ventral hernia** & 4 & 2 & 2 \\
Resection of the ileum & 3 & 3 & \\
Intussusception & 3 & 3 & 0 \\
Adhesion & 3 & 2 & 1 \\
Gastroschisis closure & 1 & 1 & \\
Gastrostomy & 2 & 2 & \\
Ileostomy & & & \\
Demanding & 1 & 1 & 0 \\
Subtotal colectomy & 1 & 1 & \\
Derotation/adhesiolysis & 1 & 1 & 1 \\
Duodenoduodenostomy & & 1 & \\
Diaphragm closure & 44 & 32 & 12 \\
Total & &
\end{tabular}

* CAPD, Continuous ambulant peritoneal dialysis

** Omphalocele

$35 \%$ of the planned procedures and $66.7 \%$ of the emergency procedures. A trainee performed $72 \%$ of all emergency procedures that were conventionally operated.

Intraoperative and postoperative complications were encountered in 12 patients $(6.9 \%)$ that underwent laparoscopic operations (see Table 4). Two complications (incomplete myotomy and bleeding) occurred in one patient. In the open group, the complication rate was 4.4\%. The conversion rate from laparoscopy to laparotomy was $7.4 \%$ (Table 5). The reason for conversion in the majority of patients $(n=4)$ was distention of the bowel and/or adhesions that prevented good overview. Intraoperative complications (i.e., bleeding) caused conversion in three patients. In four patients, a diagnostic laparoscopy identified generalized peritonitis, and in two patients, intussusception was found; all followed by conversion [10]. The small diameter of the intestine together with multiple atresia did not permit laparoscopic duodenoduodenostomy in one patient.

The mean duration of the laparoscopies did not significantly differ from the duration of the open procedures $(p=0.104)$. The duration of pyloromyotomies performed by the trainees $(n=36)$ was $44.6 \pm 15.9$ minutes versus $37.3 \pm 16.7$ minutes for staff surgeons $(n=14 ; p=\mathrm{NS})$. Follow-up median was six months (1-613 days). 
Table 3. Indications for laparoscopy by performing surgeon

\begin{tabular}{|c|c|c|c|}
\hline Laparoscopic procedures & $\begin{array}{l}\text { Total } \\
\text { number }\end{array}$ & $\begin{array}{l}\text { Performed } \\
\text { by trainees }\end{array}$ & $\begin{array}{l}\text { Performed } \\
\text { by staff } \\
\text { surgeons }\end{array}$ \\
\hline \multicolumn{4}{|l|}{ Easy } \\
\hline Appendectomy & 22 & 20 & 2 \\
\hline Diagnostic & 11 & 5 & 6 \\
\hline Hernia, inguinal rec* & 1 & 1 & 1 \\
\hline Total & 34 & 25 & 9 \\
\hline \multicolumn{4}{|l|}{ Difficult } \\
\hline Cholecystectomy & 1 & 0 & 1 \\
\hline Cholecystotomy & 1 & 0 & 1 \\
\hline Colostomy & 1 & 1 & \\
\hline Hernia, incisional & 1 & 0 & 1 \\
\hline Colectomy, subtotal & 1 & 0 & 1 \\
\hline Gastrostomy & 39 & 36 & 3 \\
\hline Intussusception & 2 & 2 & \\
\hline Perforation & 1 & 0 & 1 \\
\hline Pyloromyotomy & 50 & 36 & 14 \\
\hline Splenectomy & 7 & 3 & 4 \\
\hline Thal & 16 & 11 & 5 \\
\hline Transverso-transversostomy & 1 & 0 & 1 \\
\hline Abscess evacuation & 1 & 1 & 0 \\
\hline Total & 122 & 90 & 32 \\
\hline \multicolumn{4}{|l|}{ Demanding } \\
\hline Duodenoduodenostomy & 7 & 0 & 7 \\
\hline Gastrocolic fistula & 1 & 0 & 1 \\
\hline Hirschsprung, Duhamel & 1 & 0 & 1 \\
\hline Ileorectal anastomosis* & 1 & 0 & 1 \\
\hline Ileumresection* & 1 & 0 & 1 \\
\hline Kasai* & 4 & 0 & 4 \\
\hline $\begin{array}{l}\text { Laparoscopic-assisted } \\
\text { cecumresection }\end{array}$ & 1 & 0 & 1 \\
\hline Obstruction, adhesiolysis & 5 & 2 & 3 \\
\hline Pyloromyotomy, redo** & 4 & 2 & 2 \\
\hline Rectosigmoidres, transanal* & 1 & 0 & 1 \\
\hline $\begin{array}{l}\text { Retroperitoneal lymph } \\
\text { node biopsy }\end{array}$ & 1 & 1 & \\
\hline Diaphragm closure & 1 & 0 & 1 \\
\hline $\begin{array}{l}\text { Subtotal colectomy with } \\
\text { J-pouch* }\end{array}$ & 1 & 0 & 1 \\
\hline Thal, redo & 2 & 0 & 2 \\
\hline Total & 31 & 5 & 26 \\
\hline
\end{tabular}

* New procedure performed laparoscopically since 1998

** Two were referred from elsewhere

\section{Discussion}

In the Wilhelmina University Children's hospital in $2005,81 \%$ of 231 abdominal procedures were performed by minimally invasive surgery, compared to $60 \%$ of 244 procedures in 1998 [6]. Since 1998, the conversion rate has decreased from 10 to $7.4 \%$, whilst the complication rate remained unchanged $(6.8 \%$ in 1998 vs. $6.9 \%$ in 2005; Tables 4 and 5). The indication for laparoscopic surgery has been broadened with the addition of six different procedures, five of which are amongst the most difficult operations. This increase in the use of laparoscopic procedures during the past seven years is partly due to complete establishment of the laparoscopic approach by the surgeons, and probably also due to the acceptance and skills of staff (i.e., anesthetists, nurses).

Meanwhile, children in the open group were significantly smaller and younger than in the laparoscopic group ( $p<0.001$ and $p=0.001$, respectively), indicating that there is specific a group of patients deemed not suitable for laparoscopic surgery. In addition, more
Table 4. Intraoperative and postoperative complications in all laparoscopies $(n=187)$

\begin{tabular}{|c|c|c|c|}
\hline & $\begin{array}{l}\text { Total } \\
\text { number }\end{array}$ & $\begin{array}{l}\text { Number } \\
\text { performed } \\
\text { by trainees }\end{array}$ & $\begin{array}{l}\text { Number } \\
\text { performed } \\
\text { by staff } \\
\text { surgeons }\end{array}$ \\
\hline \multicolumn{4}{|l|}{ Complications of laparoscopy } \\
\hline $\begin{array}{l}\text { Incomplete myotomy } \\
\text { in pyloromyotomy }\end{array}$ & 2 & 2 & \\
\hline $\begin{array}{l}\text { Mucosal injury in pyloromyotomy, } \\
\text { laparoscopic repair }\end{array}$ & 1 & 1 & \\
\hline $\begin{array}{l}\text { Abcesses postappendectomy, } \\
\text { followed by laparotomy }\end{array}$ & 2 & 1 & 1 \\
\hline Bleeding (see conversion) & 3 & 1 & 2 \\
\hline \multicolumn{4}{|l|}{ Anastomotic leakage } \\
\hline \multicolumn{4}{|l|}{$\begin{array}{l}\text { One in duodenuduodenostomy; } \\
\text { laparoscopic repair }\end{array}$} \\
\hline One in ileoanal pouch, open repair & 2 & & 2 \\
\hline Portsite hernia, local repair & 1 & & 1 \\
\hline $\begin{array}{l}\text { Dysphagia after reflux surgery, } \\
\text { laparoscopic repair }\end{array}$ & 1 & & 1 \\
\hline Tear endobag in appendectomy & 1 & 1 & \\
\hline Total & 13 & 6 & 7 \\
\hline
\end{tabular}

Table 5. Events leading to conversion and laparotomy by performing surgeon

\begin{tabular}{|c|c|c|c|}
\hline Conversion & $\begin{array}{l}\text { Total } \\
\text { number }\end{array}$ & $\begin{array}{l}\text { Number } \\
\text { performed } \\
\text { by trainees }\end{array}$ & $\begin{array}{l}\text { Number } \\
\text { performed } \\
\text { by staff } \\
\text { surgeons }\end{array}$ \\
\hline $\begin{array}{l}\text { Lack of overview due } \\
\text { to peritonitis/adhesions }\end{array}$ & 4 & 2 & 2 \\
\hline $\begin{array}{l}\text { Lack of overview due to } \\
\text { bowel distention }\end{array}$ & 4 & 2 & 2 \\
\hline $\begin{array}{l}\text { Lesion art epigastrica in } \\
\text { appendicitis }\end{array}$ & 1 & 1 & \\
\hline $\begin{array}{l}\text { Venous bleeding crus in } \\
\text { redo-Thal }\end{array}$ & 1 & & 1 \\
\hline Bleeding, redo pyloromyotomy & 1 & & 1 \\
\hline Small diameter of the intestine & 1 & & 1 \\
\hline $\begin{array}{l}\text { Insufficient result scopic reduction } \\
\text { intussusception }\end{array}$ & 2 & 2 & \\
\hline Total & 14 & 7 & 7 \\
\hline
\end{tabular}

than half of the laparotomies performed would not benefit from an endoscopic approach, given the indications such as gastroschisis and adhesiolysis (Table 2).

The operating time of the laparoscopic group was not significantly longer than that of the open group, reflecting that laparoscopy has become a standard procedure. This adds favor for minimally invasive procedures: Laparoscopy does not take longer, and therefore does not affect operating schedules in a negative manner. Moreover, the duration of surgery performed by trainees is no different than when the same procedures are performed by staff surgeons. This contradicts the concern expressed by some that the trainees might not be able to gain sufficient expertise.

We found that a trainee was the operating surgeon in as many as $64.2 \%$ of all laparoscopic procedures, and $48 \%$ of all minimally invasive procedures classified as difficult (Table 3). All together, the complication and 
conversion rates were not increased in the patients on which trainees operated as compared to staff surgeons.

Trainees in a pediatric laparoscopic training center can perform laparoscopic procedures in children with good results, which is in concordance with the findings of others [11]. As we described earlier, trainees learned to perform a laparoscopic pyloromyotomy, which can be classified as an easy procedure, without an increase in the complication rate [7]. In this study, we have shown that the more difficult procedures are equally well performed by trainees. Furthermore, the increase in laparoscopic procedures as opposed to conventional procedures does not imply that trainees perform fewer procedures: they are still able to perform a significant amount of operations, and develop skills in minimal invasive surgery.

In conclusion, in a pediatric laparoscopic training center, up to $81 \%$ of all abdominal procedures are currently performed by minimally invasive surgery. Operating time is no different between laparoscopy and conventional surgery. Residents or fellows do not take significantly longer to operate than staff surgeons. In addition, the trainees perform up to $64 \%$ of all laparoscopic procedures, which indicates not only that they are able to perform more difficult procedures, but also that minimally invasive surgery does not necessarily hamper surgical training.

\section{References}

1. Bax NM (2005) Laparoscopic surgery in infants and children. Eur J Pediatr Surg 15: 319-324

2. Zitsman JL (2006) Pediatric minimal-access surgery: update 2006. Pediatrics 118: 304-308

3. Davenport M (2003) Laparoscopic surgery in children. Ann R Coll Surg Engl 85: 324-330

4. Duckett JW (1994) Pediatric laparoscopy: prudence, please. J Urol 151: 742-743

5. Delarue A, Guys JM, Louis-Borrione C, Simeoni J, Esposito C (1994) Pediatric endoscopic surgery: pride and prejudice. Eur J Pediatr Surg 4: 323-326

6. Ure BM, Bax NM, van der Zee DC (2000) Laparoscopy in infants and children: a prospective study on feasibility and the impact on routine surgery. J Pediatr Surg 35: 1170-1173

7. van der Bilt JD, Kramer WL, van der Zee DC, Bax NM (2004) Laparoscopic pyloromyotomy for hypertrophic pyloric stenosis: impact of experience on the results in 182 cases. Surg Endosc 18: 907-909

8. Costi R, Denet C, Sarli L, Perniceni T, Roncoroni L, Gayet B (2003) Laparoscopy in the last decade of the millennium: have we really improved? Surg Endosc 17: 791-797

9. Metzelder ML, Jesch N, Dick A, Kuebler J, Petersen C, Ure BM (2006) Impact of prior surgery on the feasibility of laparoscopic surgery for children: a prospective study. Surg Endosc 20: 17331737

10. van der Laan M, Bax NM, van der Zee DC, Ure BM (2001) The role of laparoscopy in the management of childhood intussusception. Surg Endosc 15: 373-376

11. Gollin G, Moores D, Baerg JC (2004) Getting residents in the game: an evaluation of general surgery residents' participation in pediatric laparoscopic surgery. J Pediatr Surg 39: 78-80 